\title{
Jean-Pierre Camus, Les Euenemens singuliers
}

\section{Daniela Dalla Valle}

\section{(Q) OpenEdition}

\section{Journals}

\section{Edizione digitale}

URL: https://journals.openedition.org/studifrancesi/6263

DOI: 10.4000/studifrancesi.6263

ISSN: 2427-5856

\section{Editore}

Rosenberg \& Sellier

\section{Edizione cartacea}

Data di pubblicazione: 1 novembre 2010

Paginazione: 547

ISSN: 0039-2944

\section{Notizia bibliografica digitale}

Daniela Dalla Valle, «Jean-Pierre Camus, Les Euenemens singuliers», Studi Francesi [Online], 162 (LIV

III) | 2010, online dal 30 novembre 2015, consultato il 21 septembre 2021. URL: http://

journals.openedition.org/studifrancesi/6263 ; DOI: https://doi.org/10.4000/studifrancesi.6263

\section{Questo documento è stato generato automaticamente il 21 septembre 2021.}

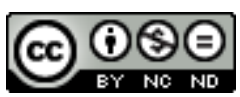

Studi Francesi è distribuita con Licenza Creative Commons Attribuzione - Non commerciale - Non opere derivate 4.0 Internazionale. 


\section{Jean-Pierre Camus, Les Euenemens singuliers}

Daniela Dalla Valle 


\section{NOTIZIA}

JEAN-PIERRE CAMUS, Les Euenemens singuliers, éd. Max Vernet, Paris, Classiques Garnier, 2010, pp. 999.

1 Le edizioni Classiques Garnier presentano, nella collana «textes de la Renaissance», l'edizione di una raccolta di novelle di Jean-Pierre Camus, pubblicata nel 1628 a Lyon e ripubblicata a Parigi nel 1660. Si tratta della prima edizione di novelle di Camus, e l'edizione ripresa è la prima, quella del 1628, l'unica stampata durante la vita di Camus.

Les Euenemens singuliers segnano dunque l'inizio di un periodo estremamente proficuo nell'attività letteraria del vescovo di Belley, quello dedicato alla novellistica, che avrà poi un enorme successo. Il volume comprende settanta novelle, raggruppate in quattro parti, precedute da un'interessante prefazione che colloca il testo in un quadro del genere nouvelle, tra Boccaccio e Bandello - stimati per la lingua e lo stile, ma criticati per «tant d'impuritez, d'impietez, de fadaises», «telles ordures \& abominations» -, gli spagnoli Cervantes e Agreda-«moins insolens»-e alcuni francesi, fra cui emerge Charles Sorel per le sue Nouvelles françaises, uscite da pochi anni, «qui surpassent de bien loin les Italiennes, \& qui ne doiuent rien aux Espagnoles».

3 L'edizione è preceduta da una presentazione di 50 pagine, che si sofferma sull'autore e sul testo (il racconto, la lingua, le fonti). Esse si propongono di illustrare «une édition de travail évitant toute interprétation», come sottolinea Max Vernet. Il testo è poi seguito da un Glossaire-concordance, da una serie di riassunti delle settanta novelle, con il rinvio - quando è necessario - alla fonte abbondantemente usata che è il Thresor d'histoires admirables di Simon Gulart; infine una bibliografia e l'indice dei personaggi e dei nomi. 